\title{
Seasonal predictability of the 2010 Russian heat wave
}

\author{
P. Katsafados ${ }^{1}$, A. Papadopoulos ${ }^{2}$, G. $\operatorname{Varlas}^{1}$, E. Papadopoulou ${ }^{1}$, and E. Mavromatidis ${ }^{1}$ \\ ${ }^{1}$ Department of Geography, Harokopio University of Athens, 70 El. Venizelou Str., P.O. Box 17671, Athens, Greece \\ ${ }^{2}$ Institute of Marine Biological Resources and Inland Waters, Hellenic Centre for Marine Research, P.O. Box 712, 19013, \\ Anavyssos Attikis, Greece \\ Correspondence to: P. Katsafados (pkatsaf@hua.gr)
}

Received: 29 August 2013 - Published in Nat. Hazards Earth Syst. Sci. Discuss.: 26 September 2013

Revised: 17 March 2014 - Accepted: 25 March 2014 - Published: 18 June 2014

\begin{abstract}
The atmospheric blocking over eastern Europe and western Russia that prevailed during July and August of 2010 led to the development of a devastating Russian heat wave. Therefore the question of whether the event was predictable or not is highly important. The principal aim of this study is to examine the predictability of this high-impact atmospheric event on a seasonal timescale. To this end, a set of dynamical seasonal simulations have been carried out using an atmospheric global circulation model (AGCM). The impact of various model initializations on the predictability of this large-scale event and its sensitivity to the initial conditions has been also investigated. The ensemble seasonal simulations are based on a modified version of the lagged-average forecast method using different lead-time initializations of the model. The results indicated that only a few individual members reproduced the main features of the blocking system 3 months ahead. Most members missed the phase space and the propagation of the system, setting limitations in the predictability of the event.
\end{abstract}

\section{Introduction}

During the second half of July and beginning of August of 2010, eastern Europe and western Russia experienced a strong heat wave resulting in over 55000 deaths. The wildfires in Russia amplified the impacts of the drought in the area and led to a $25 \%$ significant decrease of the annual crop production and a total loss to the local economy of more than USD 15 billion (Barriopedro et al., 2011). This heat wave was more intense compared to temperature reconstructions from the last half millennia (Sedláček et al., 2011) and covered a wider area than the heat wave over Europe during the summer of 2003 (Stott et al., 2004; Schär and Jendritzky, 2004). Such kind of mega-heat waves are more likely to break the 500-year-long seasonal temperature records over approximately $50 \%$ of Europe. According to regional multimodel experiments, the probability of a summer experiencing mega-heat waves is expected to increase by a factor of 5-10 within the next 40 years. However, the magnitude of the 2010 event was so extreme that despite this prediction, the likelihood of occurrence of a comparable event over the same region remains fairly low until the second half of the 21st century (Barriopedro et al., 2011).

The Euro-Russian heat wave resulted from a strong blocking anticyclone that persisted over eastern Europe driving warm air from Africa and the Arabian Peninsula to western Russia and leading to unprecedented temperatures. During the blocking period the orientation of the anticyclone favored a cold northerly airflow towards the Indian Ocean, which interacted with low-level warm and humid air and initiated the heavy rainfall across the Gangetic Plains between the Bay of Bengal in the east to northern Pakistan in the west (Webster et al., 2011). The intensity of this event is confirmed by the amount of precipitation received in a single day, which exceeded half of the annual rainfall (Ghelli et al., 2010).

Analysis of model simulations indicated that neither anthropogenic influences nor other slowly varying ocean boundary conditions substantially contributed to the magnitude of the event; rather, a primarily natural effect seems to have triggered the Russian heat wave. The event was mainly attributed to internal atmospheric dynamical processes that produced and maintained an intense and long-lived blocking event. However the intensity of the heat wave was further increased by regional land surface feedbacks (Dole et al., 2011). A possible scenario of positive feedback involves 
carbon products and particulate matter primarily emitted from the Russian forest fires, which would further heat the troposphere and evaporate cloud droplets. This process dynamically affects the atmospheric stability, amplifying the heat wave and strengthening the downstream Rossby wave from the large-scale blocking system and, finally, provoking the floods in Pakistan (Lau and Kim, 2012). Similar surface feedbacks and in situ processes also affected the predictability of the European heat wave in the summer of 2003 (Weisheimer et al., 2011).

For such intrinsically low-probability events, with long return period, the questions of whether the events are predictable and over what lead time are of high importance. The significance of seasonal predictions lies on their ability to provide early warnings about oncoming and extreme weather episodes that may cause human fatalities and significantly affect the infrastructure and environment. Forecasts on seasonal to intraannual timescales rely on comprehensive atmospheric global circulation models (AGCMs) usually coupled with land surface and hydrodynamic circulation models with an improved understanding among the coupling systems (Gneiting and Raftery, 2005; Hurrell et al., 2009). So, it is of great interest to understand if AGCMs are able to resolve the main atmospheric mechanisms that trigger potentially intense phenomena on various spatiotemporal scales and, finally, to produce credible forecasts. Some studies reported that AGCM-based seasonal forecasts may provide useful information especially on large-scale phenomena (e.g., El Niño and La Niña) and reveal their likely influences on regional climate (Shapiro et al., 2010). Other studies evidenced that the predictability of seasonal weather statistics is also possible (Palmer and Anderson, 1994; Hastenrath, 1995; Rowell, 1998). However, some of them reported difficulties to predict summer mean precipitation anomalies in northwestern Asian monsoon events even for a 0-month lead forecast, although they are capable of predicting zonal wind anomalies at $850 \mathrm{hPa}$ several months ahead and, consequently, satisfactorily predict summer monsoon circulation (Lee et al., 2011). A computationally feasible approach in order to accomplish reasonable predictions on a seasonal timescale is through ensemble forecasting in which several model forecasts are performed by introducing perturbations in the initial conditions or in the models themselves (Kalnay, 2003; Chowdary et al., 2010).

In this context, the principal aim of this study is to examine the predictability of the Russian heat wave on a seasonal timescale. The dynamical seasonal simulations have been carried out using the Community Atmosphere Model (CAM; Collins et al., 2004) of the National Center for Atmospheric Research (NCAR). A modified version of the lagged average forecast method using different lead-time initializations of the model has been adopted. The impact of various model initializations on the predictability of this large-scale event has been also investigated, because such comprehensive prognostic systems are sensitive to the initial conditions. This is due to the fact that the chaotic nature of the atmosphere imposes a finite limit of a few weeks to the predictability of the atmospheric conditions (Kalnay, 2003; Matsueda, 2011). Therefore, an ensemble forecasting method was introduced in the context of numerical weather prediction. Ensemble forecasting is assumed as a feasible method to integrate a deterministic forecast with an estimate of the probability distribution of atmospheric states (Buizza, 1997).

\section{Description of the synoptic conditions}

The nature of the Russian heat wave and its origins were associated to the upper-level atmospheric circulation. During summer 2010 the typical upper-level atmospheric circulation over Asia was differentiated and the Rossby wave anomalies invoked extreme phenomena. An omega blocking pattern characterized the $500 \mathrm{hPa}$ July 2010 flow (Dole and Gordon, 1983). The blocking anticyclone over Russia was the dominant weather pattern prevailing in Europe from late July to mid-August 2010 while the low frequency subtropical jet meanders around it, increasing the meridional component of the anomalous flow at $500 \mathrm{hPa}$ over eastern Europe transferring warm air at $850 \mathrm{hPa}$ (Fig. 1). Moreover, a widespread ridge at $500 \mathrm{hPa}$ extended from the Middle East to eastern Europe and contributed to the formation of the omega blocking pattern. The synergistic effect of the upper air ridge and the surface anticyclone secluded Russia from the westerly airflow and intensified the omega block (Fig. 2). The heat wave was trapped over Russia for about 3 weeks resulting in increasingly high surface temperatures in the area. Furthermore, the high levels of 1000-500 hPa thickness amplified the warm air mass depth (Fig. 3). This rapid geopotential height rise during the blocking development is characterized as a synoptic-scale pattern or as an interaction between synoptic- and planetary-scale processes (Lupo and Smith, 1998).

As it was recorded from the meteorological stations in the area, the highest July 2010 surface temperature anomalies occurred near the center of the blocking (Table 1), where northward displaced subtropical air, descending air motions and reduced cloudiness all contributed to abnormally warm surface temperatures (Ghelli et al., 2010). Severe drought occurred with the Russian heat wave, making it likely that land surface feedbacks amplified the heat wave intensity, as has been observed in prior severe droughts (Fischer et al., 2007). Thus, during nighttime the cooling of the ground surface intensified the temperature inversion, resulting in amplification of the anticyclone. The vertical temperature profile over Moscow revealed an intense inversion layer coexisting with a dry air mass in the lower troposphere (Fig. 4).

To the east of the omega block, anomalously cool temperatures occurred in conjunction with an upper level trough and southward advection of polar air (Dole et al., 2011). As it is shown in Fig. 5, a subtropical jet streak at the level of 


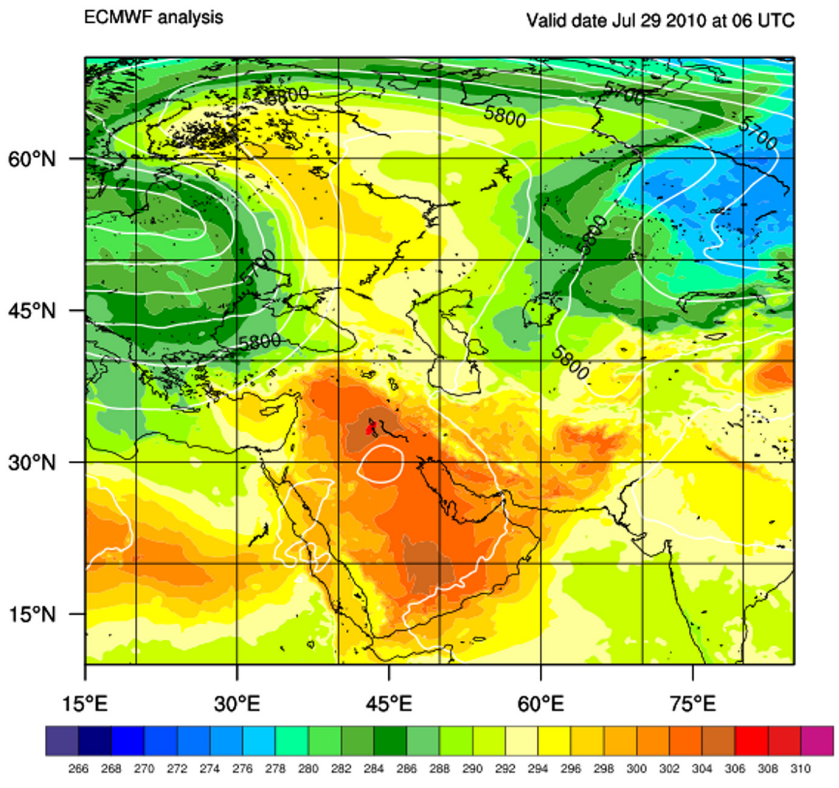

Figure 1. Temperature at $850 \mathrm{hPa}$ (color shaded in $\mathrm{K}$ ) and geopotential height at $500 \mathrm{hPa}$ (contours in gpm - geopotential meters) for 29 July at 06:00 UTC. Data are based on the ECMWF operational analysis.

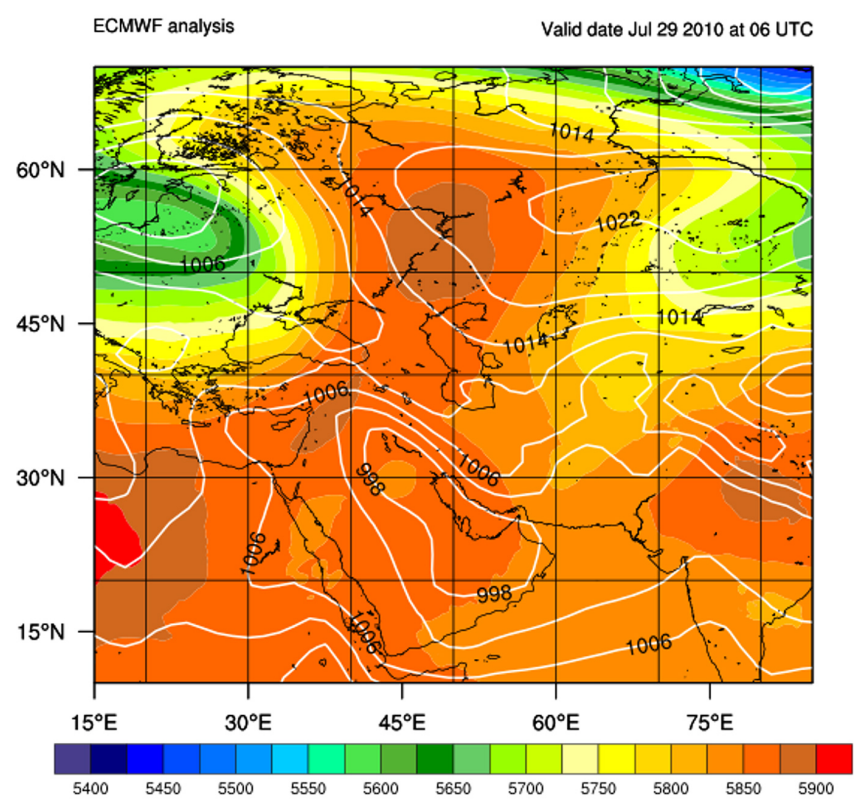

Figure 2. Mean sea level pressure (contours in hPa) and geopotential height at $500 \mathrm{hPa}$ (color shaded in gpm) for 29 July at 06:00 UTC. Data are based on the ECMWF operational analysis.

$200 \mathrm{hPa}$ intensified the divergence in this level and the convergence at the surface level (Uccellini and Johnson, 1979). The interaction between this upper-level jet streak and diabatic processes initiated heavy rainfalls in a widespread area of northern Pakistan.

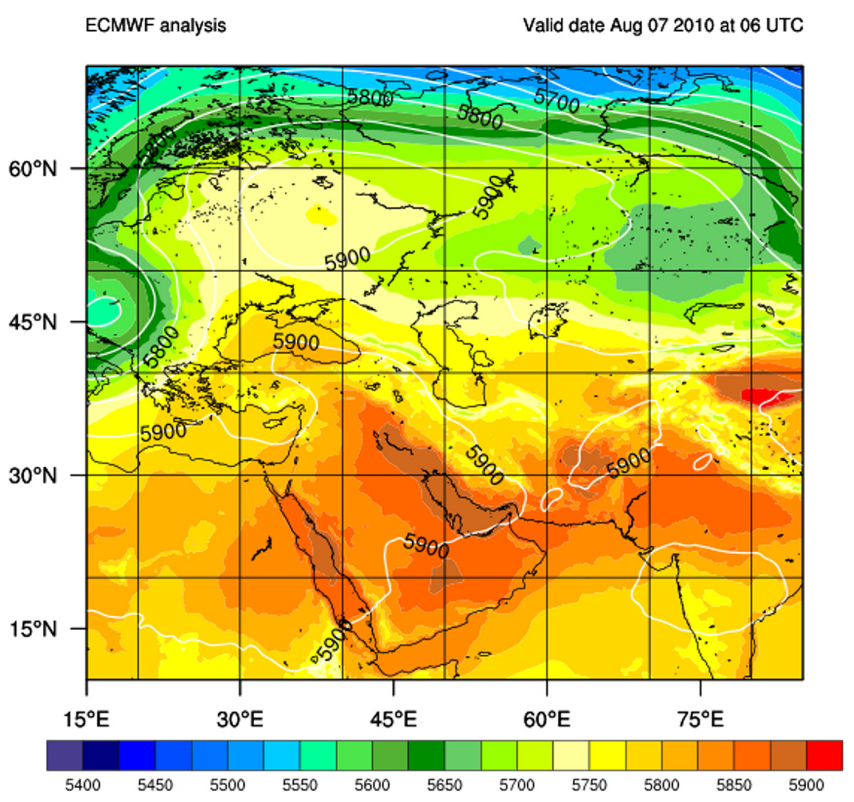

Figure 3. $1000-500 \mathrm{hPa}$ thickness (color shaded in gpm) and geopotential height at $500 \mathrm{hPa}$ (contours in gpm) for 7 August at 06:00 UTC. Data are based on the ECMWF operational analysis.

Table 1. Maximum near-surface temperatures recorded at four meteorological stations in Russia, Belarus and Finland (source: ECMWF).

\begin{tabular}{lll}
\hline Met. Station & Coordinates & Max. Temp. $\left({ }^{\circ} \mathrm{C}\right)$ \\
\hline Jaskul (Russia) & $46.1^{\circ} \mathrm{N}, 45.2^{\circ} \mathrm{E}$ & $42.2(8 / 8 / 2010)$ \\
Moscow (Russia) & $55.5^{\circ} \mathrm{N}, 37.4^{\circ} \mathrm{E}$ & $39(30 / 7 / 2010)$ \\
Gomel (Belarus) & $52.2^{\circ} \mathrm{N}, 30.6^{\circ} \mathrm{E}$ & $38.9(7 / 8 / 2010)$ \\
Joensuu (Finland) & $62.4^{\circ} \mathrm{N}, 29.4^{\circ} \mathrm{E}$ & $37.2(29 / 7 / 2010)$ \\
\hline
\end{tabular}

\section{Model description and methodology}

In this study, the seasonal predictability of the Russian heat wave is investigated using the NCAR CAM (version 3), which is the atmospheric component of the Community Climate System Model (CCSM). CAM3 is an AGCM designed to produce simulations for several different dynamical cores and horizontal resolutions. A detailed description of the physics and dynamics of CAM 3 can be found in Collins et al. (2004, 2006). The standard version, used in this study, has 26 vertical levels and an 85-wave triangular spectral truncation (T85L26). The specific Eulerian truncation corresponds to a zonal resolution of $1.41^{\circ} \times 1.41^{\circ}$. In CAM3, the physics and Eulerian or semi-Lagrangian dynamical cores are process-split, while the physics and finitevolume (FV) cores are time-split (Williamson, 2002). The diagnostic cloud-water scheme used in a previous version of the model has been replaced by the prognostic cloud-water parameterization of Rasch and Kristjánsson (1998) updated by Zhang et al. (2003). Concerning the radiative process, 


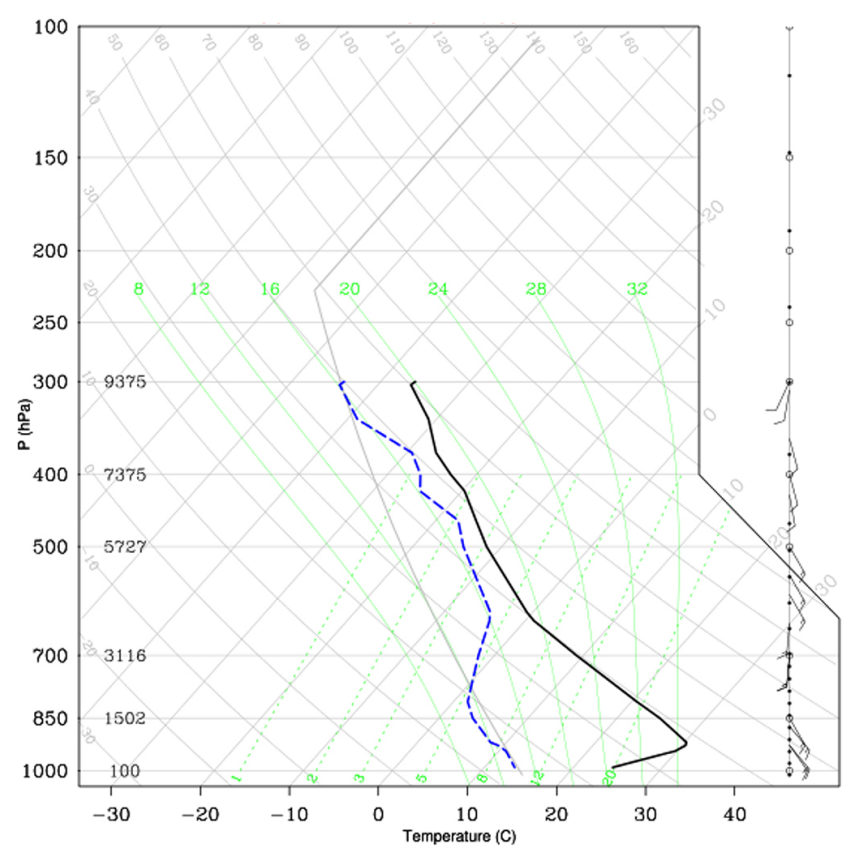

Figure 4. Skew-T diagrams of Moscow (WMO ID: 27612) for 29 July at 00:00 UTC. Radiosonde data are provided by the ECMWF.

the model includes separate evolution equations for the liquid and ice-phase condensate and the revised scheme includes a new formulation of the fractional condensation rate and a self-consistent treatment of the evolution of water vapor, heat, cloud fraction, and in-cloud condensate (Zhang et al., 2003). The aerosol data set includes the annually cyclic, monthly mean distributions of sulfate, sea salt, carbonaceous, and soil-dust aerosols. The climatology is derived from a chemical transport model constrained by assimilation of satellite retrievals of aerosol depth (Collins et al., 2001). The climatology in CAM3 is obtained from aerosol assimilation for the period 1995-2000. CAM3 also includes the Community Land Model (CLM) for the treatment of land surface energy exchanges. The model examines the physical, chemi$\mathrm{cal}$, and biological processes by which terrestrial ecosystems affect and are affected by climate across a variety of spatial and temporal scales (Oleson et al., 2004). Stand-alone integrations with CAM3 employ a global sea surface temperature (SST) and sea-ice conditions (SIC) data sets similar to those utilized by the ECMWF (European Centre for Medium-Range Weather Forecasts; Fiorino, 2004) based on the 40-year reanalysis project (ERA-40).

In this study the performance of the model has been assessed by simulating the large-scale blocking system developed over eastern Europe and Russia in July and August of 2010. To this end, seasonal simulations of the CAM 3 coupled with the CLM have been carried out using a time-variant climatological SST data set for the definition of the sea surface boundary condition. The simulations were based on a modified version of the lagged average forecast (LAF) formula-

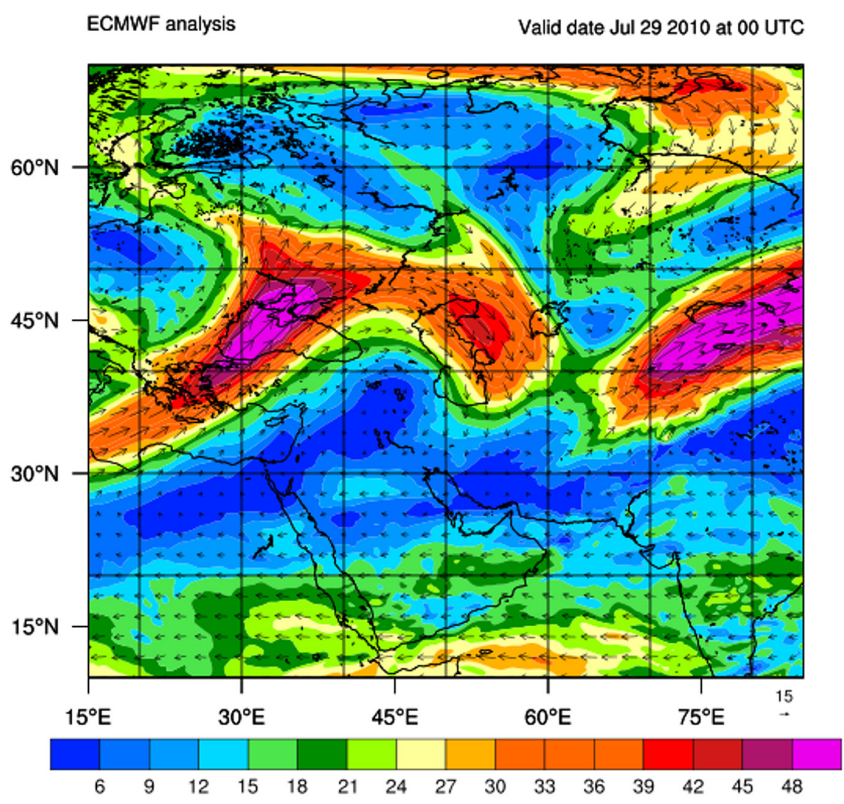

Figure 5. Wind speed (color shaded in $\mathrm{m} \mathrm{s}^{-1}$ ) and direction at $200 \mathrm{hPa}$ for 29 July at 00:00 UTC. Data are based on the ECMWF operational analysis.

tion introduced by Hoffman and Kalnay (1983). In a shortrange forecast the LAF method consists of ensemble members that include the latest operational forecast, and also forecasts for the same verification time started a few days earlier than the latest one (Dalcher et al., 1988). Thus each member includes the governing dynamics and it can be considered as a perturbation about the ensemble mean. In accordance to the LAF methodology, CAM3 seasonal-scale simulations were initialized from the daily global analysis assuming each analysis as a perturbation of the previous one due to the long lead time of 2-7 months ahead. Thus, the ensemble consists of 61 members with different initialization dates and different simulation lengths, but with identical end time. In particular, each member was initialized by the Global Forecasting System (GFS) analyses at 00:00 UTC (Universal Time Coordinated) of each day of January and April 2010 and performed a simulation up to 1 September at 00:00 UTC. Hence, the first model run (member) was initialized by the 00:00 UTC 1 January GFS analysis and performed the simulation for 8 months (243 days). The second run started at 00:00 UTC 2 January and produced a simulation of 242 days. Likewise, the member 32 was initialized by the 00:00 UTC 1 April GFS analysis and integrated for a period of 5 months (153 days). Finally, the last ensemble member was initialized by the 00:00 UTC 30 April 2010 GFS analysis with simulation period of 4 months (124 days).

In this way, 31 members were produced with 5-8 months lead time for the period of June, July and August (JJA) and 30 members were produced with 2-5 months lead time for the same period (Fig. 6). In order to assign the estimated 


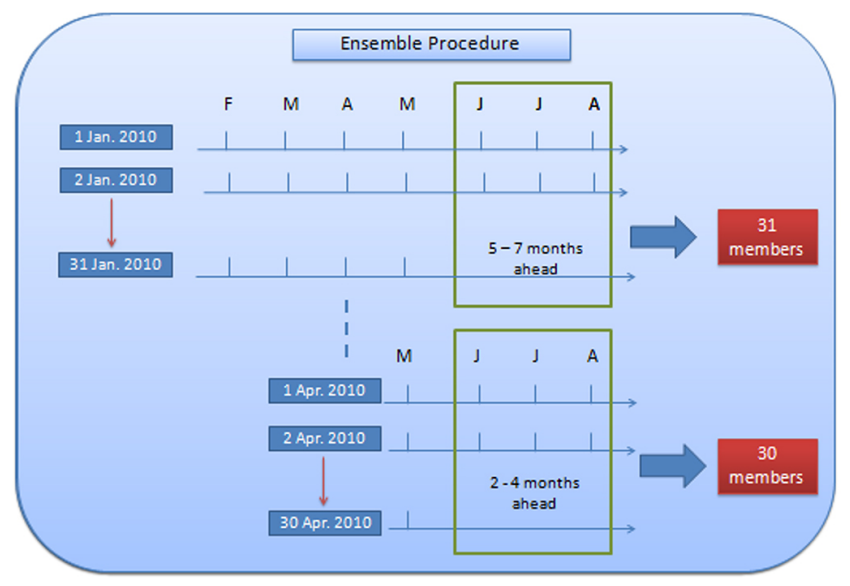

Figure 6. Schematic representation of the seasonal simulations ensemble procedure.

temperature anomaly, monthly averaged model outputs were compared against long-term monthly means valid for the period of 1971-2000, released by the National Center for Environmental Predictions (NCEP) and NCAR (Kalnay et al., 1996). Moreover, spaghetti plots of the temperature at $850 \mathrm{hPa}$ have been also produced as a guidance provision of each member uncertainty.

\section{Predictability of the atmospheric blocking}

\subsection{Temperature at $850 \mathrm{hPa}$ and geopotential height at $500 \mathrm{hPa}$}

The simulated temperature at $850 \mathrm{hPa}$ and geopotential height at $500 \mathrm{hPa}$ of individual ensemble members are compared against the relevant ECMWF operational analyses in order to evaluate the predictability of the event. Some members indicate an early warning of the event and reveal the large-scale spatiotemporal characteristics of the blocking system that prevailed over Russia even 3 months in advance. For instance, the member initialized at 22 April 2010 and referenced as 0422 satisfactorily reproduced the main blocking pattern over eastern Europe for 16 July at 12:00 UTC (Fig. 7a). However this member simulated a northward extended and more intense system compared to an early staged blocking system depicted in the ECMWF analysis (Fig. 7b). Four days later the 0422 member displaced a mature stage system over central Russia while in the ECMWF analysis the blocking pattern was still in developing stages over eastern Europe (Fig. 8a, b). Despite the fact of the early warning this member missed the phase of the system and its spatiotemporal characteristics as well, predicting a short-lived eastward propagating blocking pattern. The individual member initialized at 25 April 2010 and referenced as 0425 further improved the prediction of the blocking system on 16 July at 12:00 UTC (Fig. 9a) reproducing a less northward-extended
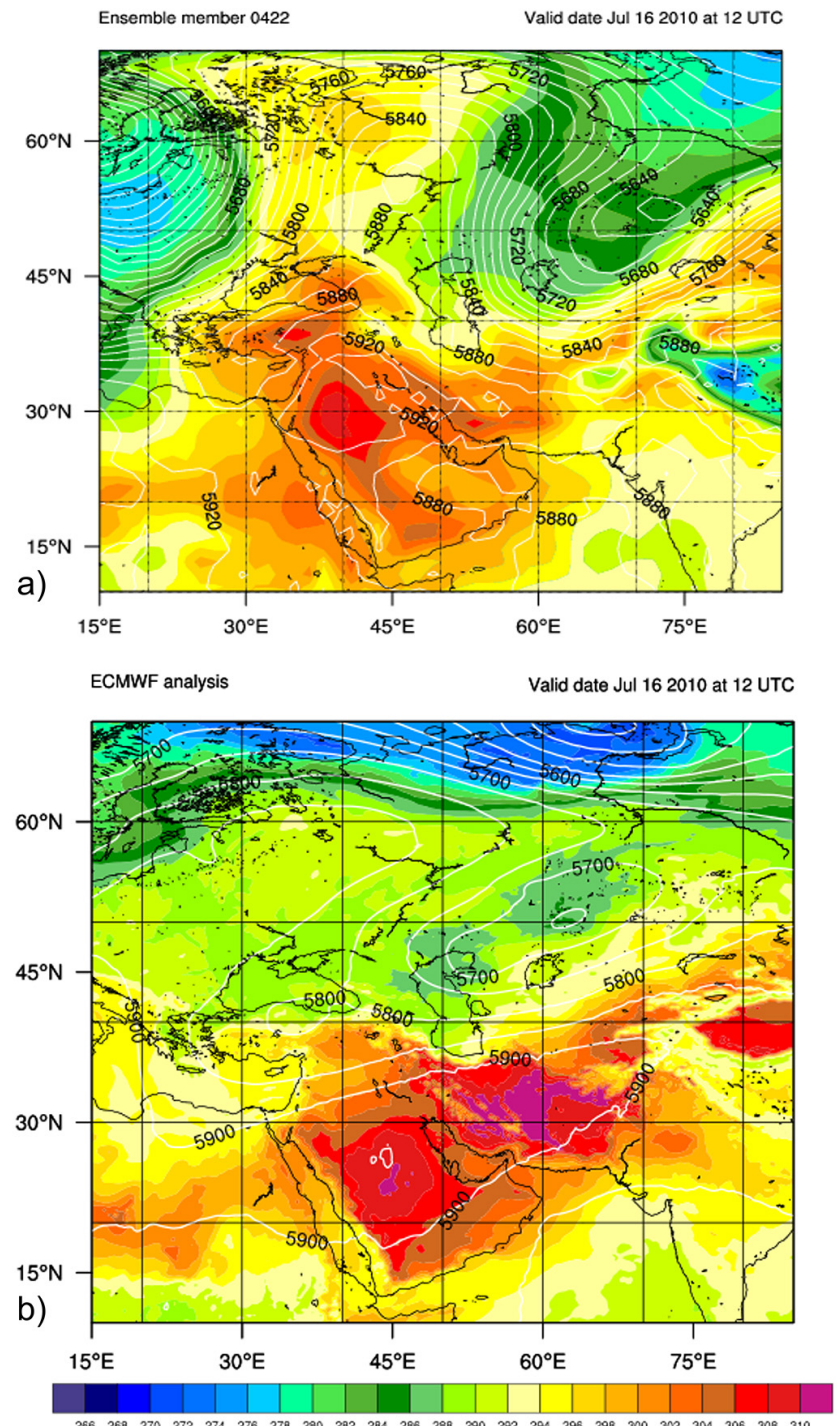

Figure 7. Temperature at $850 \mathrm{hPa}$ (color shaded in $\mathrm{K}$ ) and geopotential height (contours in gpm) at $500 \mathrm{hPa}$ for 16 July 2010 at 12:00 UTC based on (a) the ensemble member initialized at 22 April 2010 and (b) ECMWF operational analysis.

system. However the 0425 displaced the center of the system to central Russia on 20 July and predicted a short-lived blocking pattern that lasted only 5-6 days (Fig. 9b). This led to overestimation of the temperature advection to the affected area and underestimation of the polar anomaly flow eastward of the blocking system.

\subsection{Spaghetti plots of the temperature at $850 \mathrm{hPa}$}

The mean monthly isotherm of the $283 \mathrm{~K}$ obtained from each one of the 61 members is compared against the NCAR/NCEP long-term (based on the 1971-2000 period) mean monthly isothermal values of $283 \mathrm{~K}\left(10^{\circ} \mathrm{C}\right)$ and $278 \mathrm{~K}\left(5^{\circ} \mathrm{C}\right)$. This comparison determines whether the estimated temperatures 

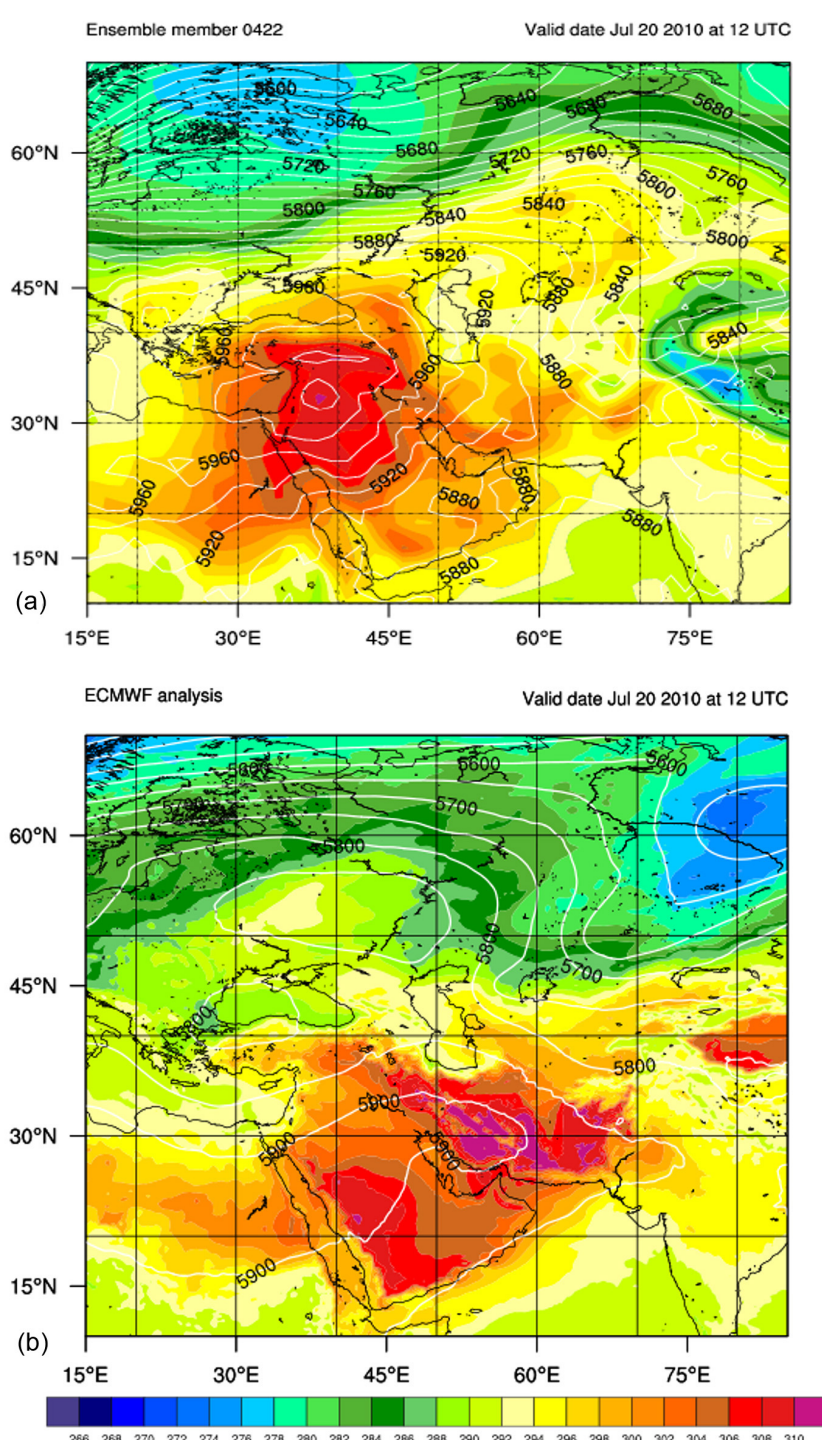

Figure 8. Temperature at $850 \mathrm{hPa}$ (color shaded in $\mathrm{K}$ ) and geopotential height (contours in gpm) at $500 \mathrm{hPa}$ for 20 July 2010 at 12:00 UTC based on (a) the ensemble member initialized at 22 April 2010 and (b) ECMWF operational analysis.

exceed the relevant climatological values for the period under consideration. In Fig. 10a almost all the members that were initialized in January 2010 exceeded the NCEP/NCAR longterm monthly mean temperature at $283 \mathrm{~K}$ for July 2010 , predicting increased occurrence probability for higher than normal temperatures over eastern Europe and Russia. But, only a few members exceeded the long-term isotherm of $278 \mathrm{~K}$, indicating that the predicted temperature anomaly is likely to be less than $5 \mathrm{~K}$. However, the recorded mean monthly temperature anomalies for July 2010 provided from the National Oceanic and Atmospheric Administration (NOAA) show that the surface temperature anomaly was more than $5^{\circ} \mathrm{C}$ over eastern Europe and Russia (Fig. 11). The spaghetti
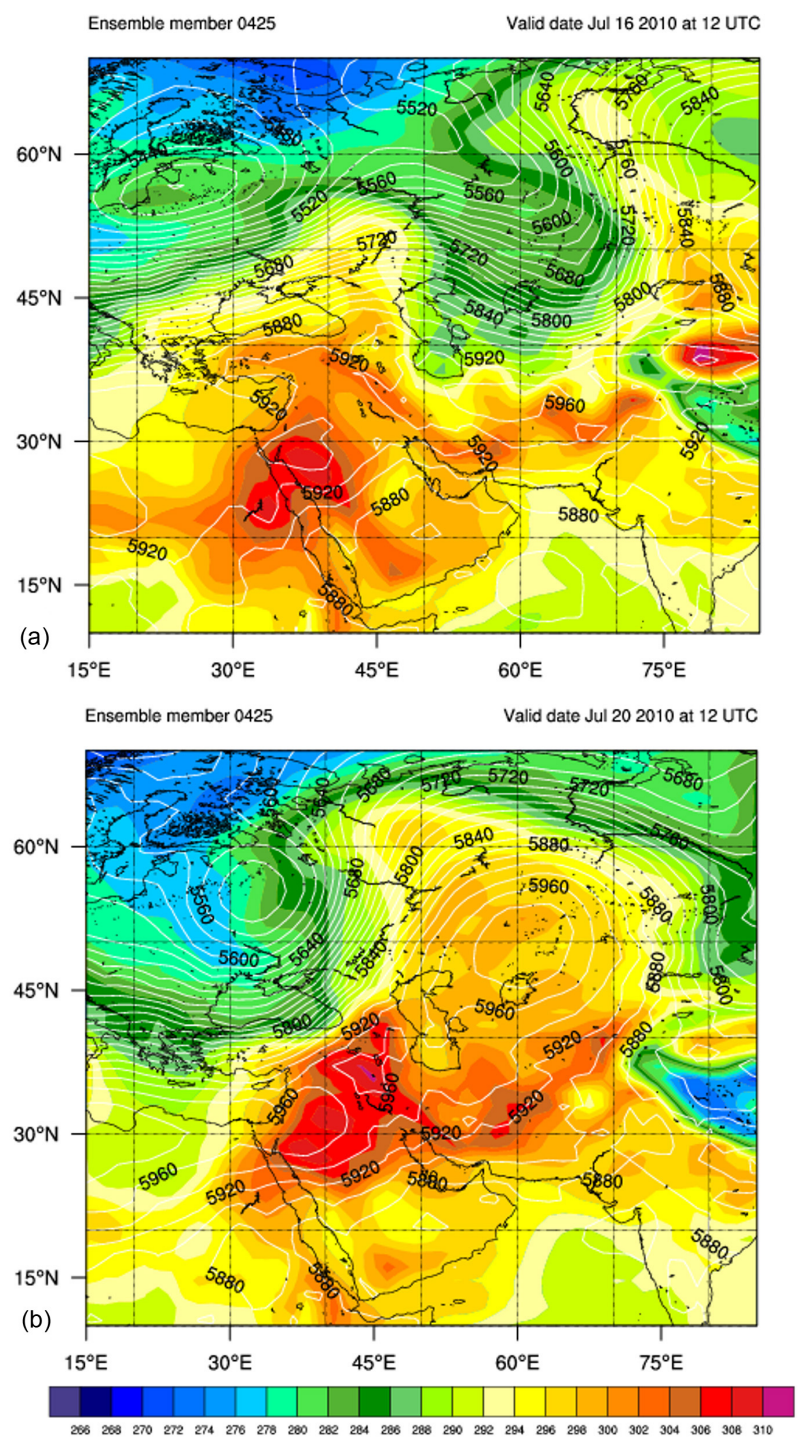

Figure 9. Temperature at $850 \mathrm{hPa}$ (color shaded in $\mathrm{K}$ ) and geopotential height (contours in gpm) at $500 \mathrm{hPa}$ at 12:00 UTC for (a) 16 July 2010 and (b) 20 July 2010 from ensemble member initialized at 25 April 2010.

plots referenced to the mean monthly temperature of $\mathrm{Au}$ gust 2010 (Fig. 10b) suggest that almost half of ensemble members exceeded the long-term isotherm of $278 \mathrm{~K}$. As it is shown in Fig. 10a and b, the divergence of the forecasts for July and August within the ensemble indicates that the uncertainty in the forecast can be high. Such reduced predictability is more prominent over the eastern flanks of the blocking system and it is associated with the eastward displacement of the system obtained from almost the entire members initialized in January 2010. The simulations for April 2010 indicate persistence, similar that in January, of higher than normal temperatures over the study area. For July 2010, most of the April members are found in the range of 278-283 K longterm means (Fig. 10c) while for August 2010 they are placed 

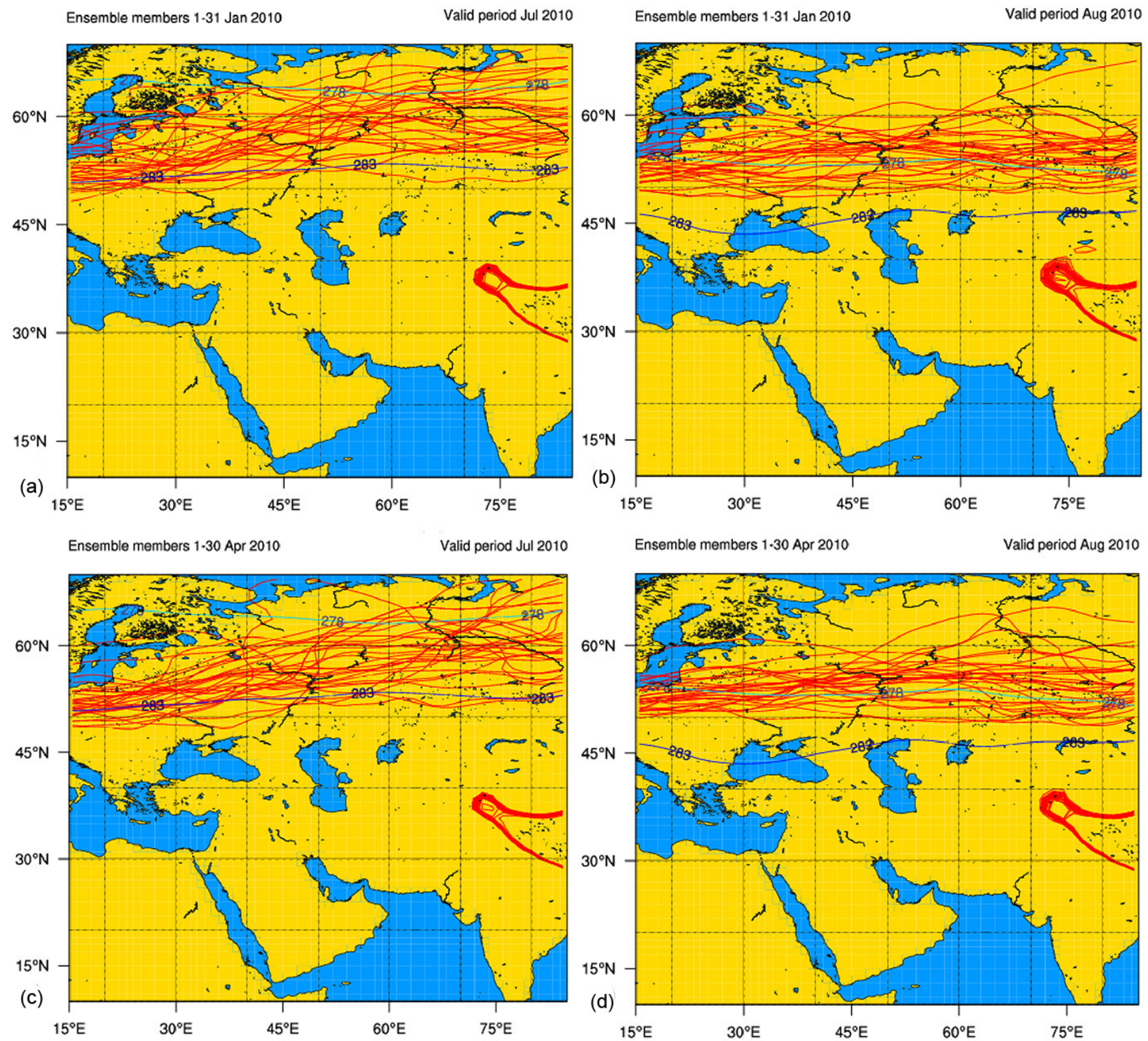

Figure 10. Spaghetti plots (solid red lines) of the July and August 2010 mean monthly temperature at $850 \mathrm{hPa}$ isotherms of $283 \mathrm{~K}\left(10^{\circ} \mathrm{C}\right)$ for the ensemble members initialized in January 2010 (a and b) and in April 2010 (c and d). NCEP long-term mean-monthly isotherms at $850 \mathrm{hPa}$ of $283 \mathrm{~K}\left(10^{\circ} \mathrm{C}\right)$ and $278 \mathrm{~K}\left(5^{\circ} \mathrm{C}\right)$ are denoted in solid blue and cyan lines respectively.

northward close to $278 \mathrm{~K}$ (Fig. 10d). For both months the ensemble spread is reduced over eastern Europe while areas of high uncertainty are located over central Russia. Despite the fact of the long lead period, both January and April members provide similar predictability confidence. Thus, April simulations provide almost negligible predictability improvement comparing against the relevant January simulations. Furthermore, the comparison between the maximum daily temperatures at $850 \mathrm{hPa}$ obtained from the ensemble members integrated over eastern Europe and Russia and the corresponding ECMWF analyses did not reveal any strong signal of the extremely warm summer (Fig. 12a and b).

\subsection{Temperature anomaly at $850 \mathrm{hPa}$}

A temperature anomaly at $850 \mathrm{hPa}$ is an indication of the model predictability compared to the NCEP/NCAR longterm monthly means. Figure 13 presents the mean monthly temperature anomaly for August 2010 simulated from the individual member 0422. An extended area over eastern Europe and western Russia is characterized by above normal temperatures of up to $+6^{\circ} \mathrm{C}$ and it was combined with a negative temperature anomaly eastward of the blocking system driving polar air masses southward and initiating torrential rains in Pakistan. Even though this indicates a 


\title{
Temperature Anomalies July 2010
}

\author{
(with respect to a 1971-2000 base period)
}

National Climatic Data Center/NESDIS/NOAA

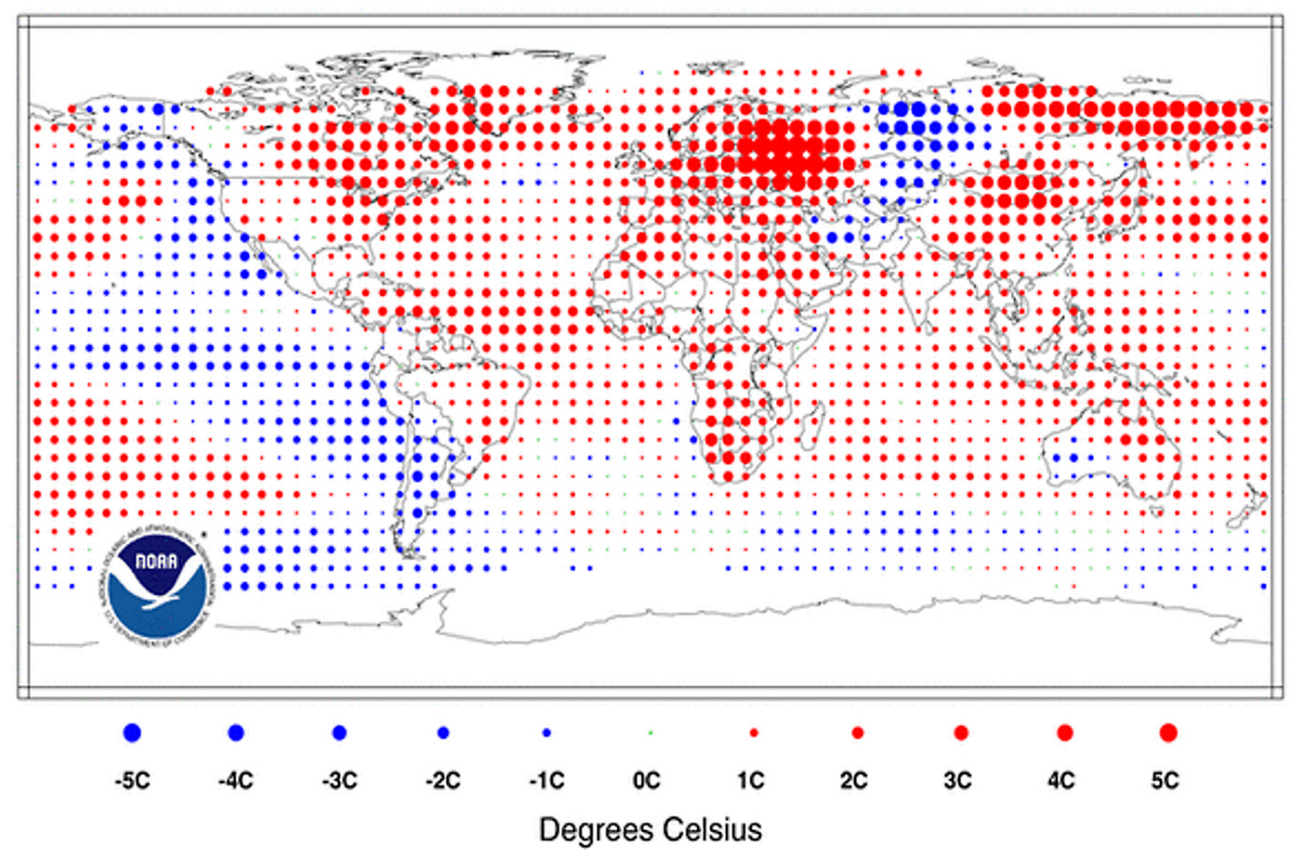

Figure 11. Mean temperature anomalies $\left({ }^{\circ} \mathrm{C}\right)$ for July 2010 with respect to the $1971-2000$ base period. (Source: National Climatic Data Center, NESDIS/NOAA).

possible predictability from some individual members almost 4 months in advance, generally this was not the case for most of the ensemble members.

Figure 14 depicts the mean monthly temperature anomalies for July and August 2010 obtained from both forecasting periods, January and April. In Fig. 14a the prevailing temperature anomaly over Russia is of up to $+2{ }^{\circ} \mathrm{C}$ while the maximum anomaly of almost $+6^{\circ} \mathrm{C}$ is located over the Middle East and the northern areas of Saudi Arabian Peninsula. This overestimation of the temperature anomaly over Russia is not considered as statistically significant in a $95 \%$ confidence level. A similar pattern is also clearly depicted in the mean August temperature anomaly obtained from the January 2010 ensemble members (Fig. 14b). The comparison against NOAA's mean monthly temperature anomalies (Fig. 12) revealed the model's inability to reproduce the local maxima of temperature anomalies. This is a strong indication of reduced predictability of a large-scale event in a lead period of 5-7 months. April members were not able to significantly increase the forecasting skill. Indeed, they simulated a secondary maxima of temperature anomalies over Balkan Peninsula and southern Russia (Fig. 14c) and it was combined with a zone of positive anomaly of up to $+2{ }^{\circ} \mathrm{C}$ extending from eastern Europe to central Russia in August 2010 (Fig. 14d). Such anomalies include high levels of un- certainty since they are not considered as statistically significant in a $95 \%$ confidence level. The above mentioned analysis confirms that almost the entire members initialized on April 2010 and having 2-5 months lead time did not provide any further predictability improvement. Thus the predictability seems to be independent to the forecast horizon varying from seasonal to intraannual timescales. This evidence is also in agreement with Matsueda's (2011) investigation of the extreme Euro-Russian blocking and of the blocking-induced extreme surface temperatures based on five operational medium-range ensemble forecasts. In this study, Matsueda concluded that the predictability of this particular event has been lost after a few weeks of simulations. Despite the few individual members in April, which resolved the main features of the blocking system almost 3 months before the event, the spread of most members (in January and April) indicates a rather short memory and therefore weak dependence from their initial conditions. Similar experiments, based on NOAA's Climate Forecast System (CFS), initialized in early June 2010, show no evidence for a change in the probability of prolonged daily blocking during July 2010 over western Russia compared to the relevant July simulations (Dole et al., 2011). Forecasts from the ECMWF Ensemble Prediction System (EPS) indicated the presence of positive anomalies over Russia, which became stronger as 

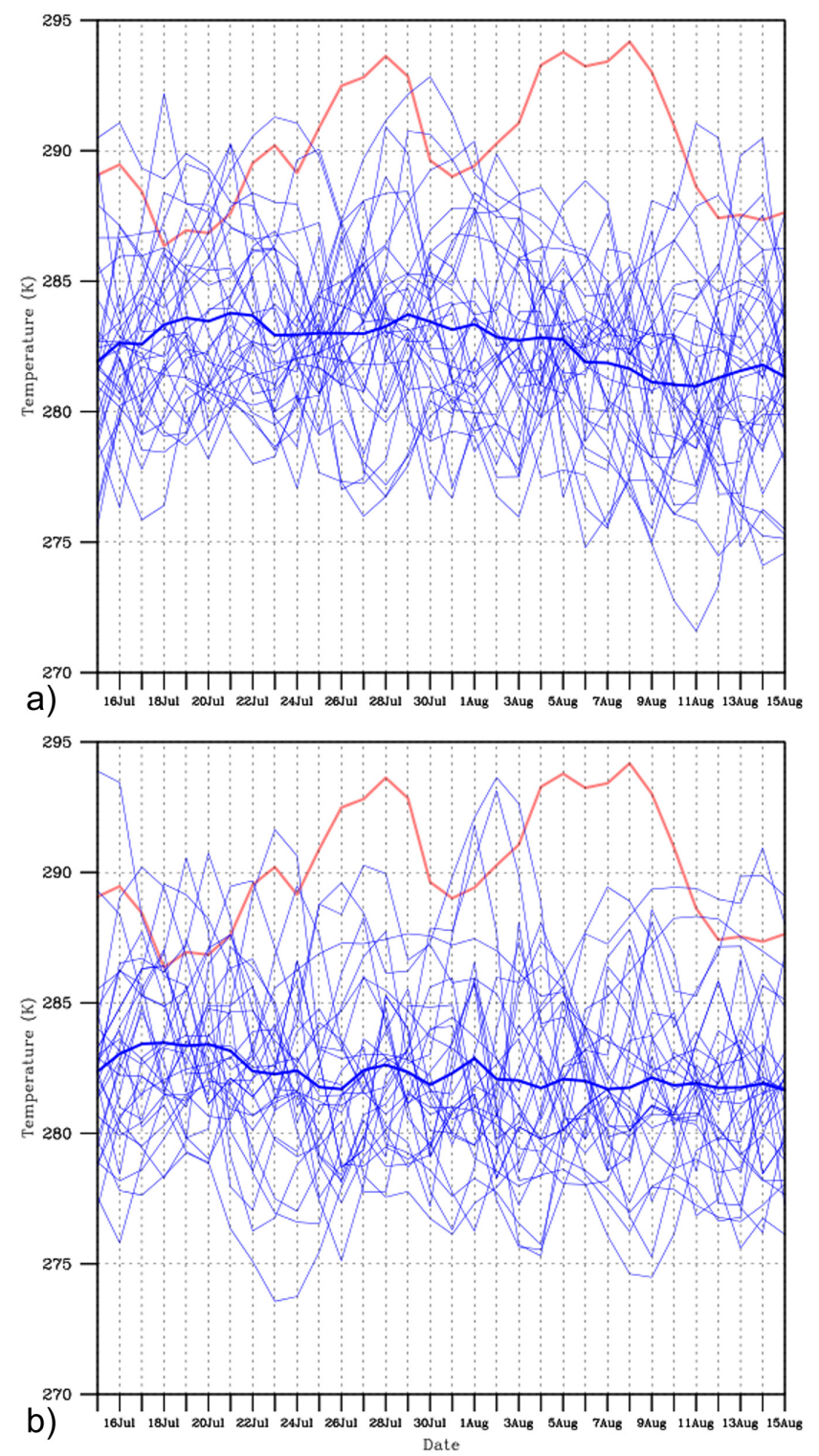

Figure 12. Maximum daily temperatures at $850 \mathrm{hPa}$ (thin blue lines) integrated over eastern Europe and Russia of the ensemble members initialized at (a) January and (b) April valid for the period July 15 to August 15, 2010. Ensemble means are denoted with thick blue lines and the red line corresponds to the ECMWF operational analyses.

the forecast lead time decreased and finally gave a good indication of the temperature anomaly over Russia three weeks in advance (Ghelli et al., 2010). These evidences provide a confirmation that the predictability of the event is limited in the few weeks before the event and that most ensemble members having 2-5 and 5-7 months of lead time are mainly dominated by high levels of uncertainty.

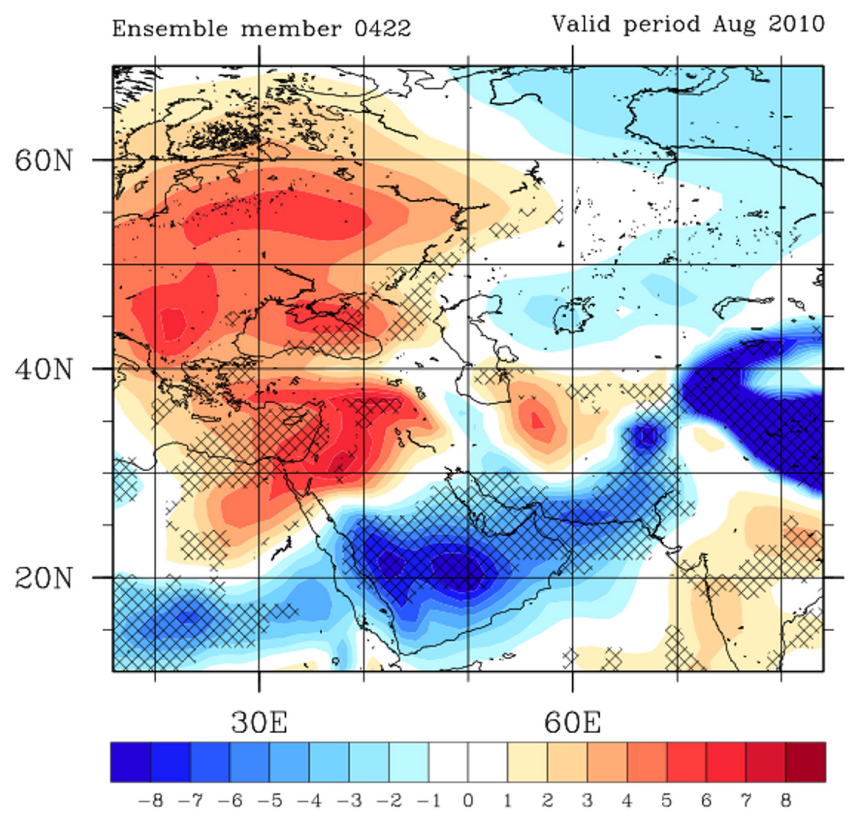

Figure 13. Mean monthly temperature anomaly (color shaded in $\mathrm{K}$ ) at $850 \mathrm{hPa}$ for August 2010 based on the ensemble member initialized on 22 April 00:00 UTC. Shaded areas exceed the $95 \%$ confidence level.

\section{Concluding remarks}

The predictability of the Russian heat wave on a seasonal timescale has been investigated in this study. The dynamical seasonal simulations have been carried out using the stateof-the-art CAM3 AGCM. The impact of various model initializations on the predictability of the event was also investigated because such comprehensive prognostic systems are sensitive to the initial conditions due to the chaotic nature of the atmosphere. According to the synoptic analysis, the Russian heat wave provoked by a strong omega blocking system persisted over eastern Europe driving warm air from Africa and the Arabian Peninsula to western Russia. The vertical temperature profile over Moscow reveals an intense inversion layer coexisting with a dry air mass in the lower troposphere resulting in amplification of the anticyclone. During the blocking period the orientation of the anticyclone favored a cold northerly airflow towards the Indian Ocean, which interacts with low-level warm and humid air and triggered heavy rainfall across northern Pakistan.

Seasonal simulations of the event were based on a modified version of the LAF method constructing 61 independent ensemble members initialized on January and April 2010. Each ensemble member has been integrated 8 and 5 months ahead respectively and in this way, for the period of JJA, 31 members were produced on a 5-8 months lead time and 30 members on a $2-5$ months lead time.

As far as the predictability is concerned, only a few individual members in April reproduced the main features of the 

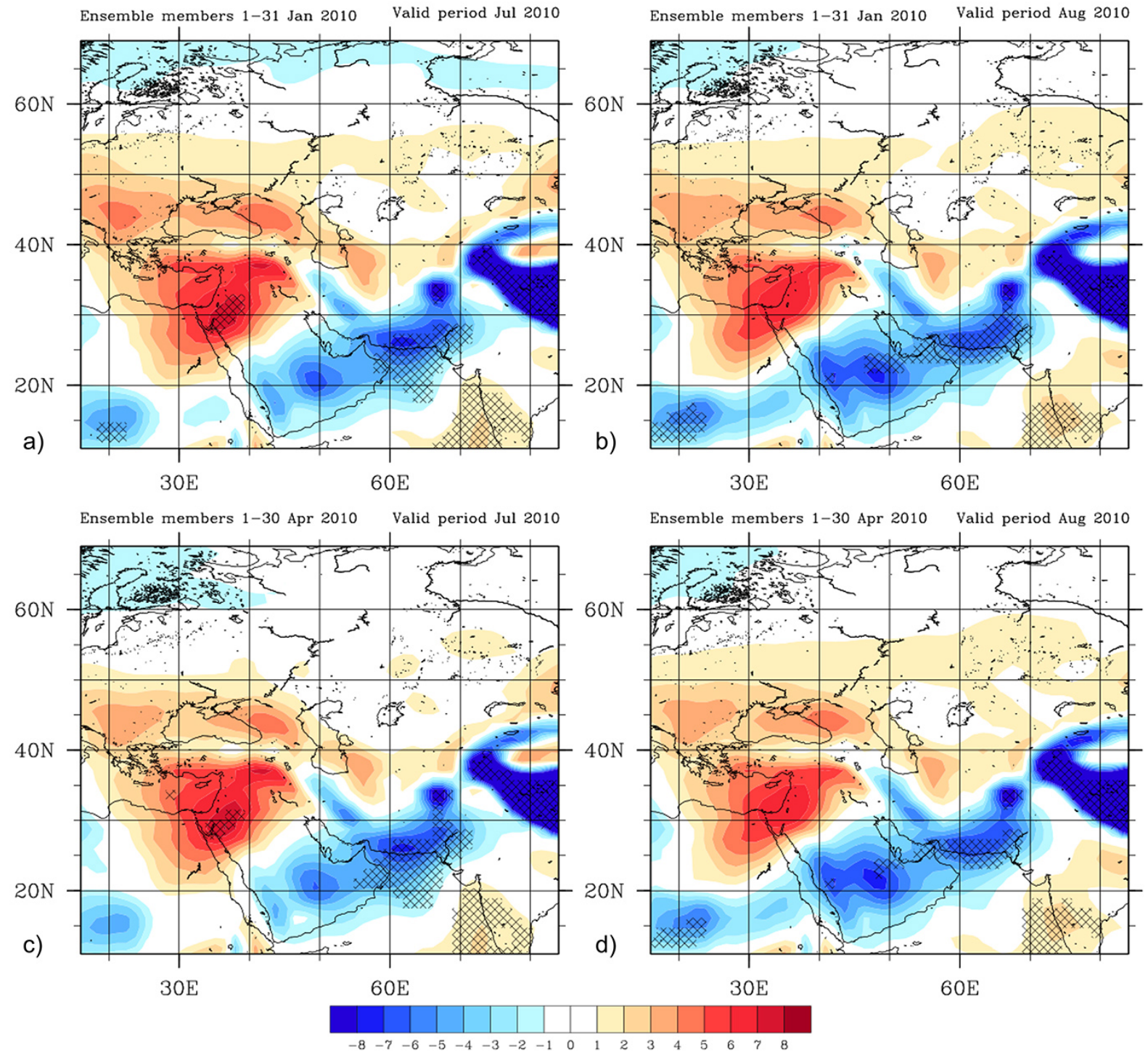

Figure 14. Mean monthly temperature anomaly (color shaded in K) at $850 \mathrm{hPa}$ for July and August 2010 based on the ensemble members initialized in January 2010 (a and b), and April 2010 (c and d). Shaded areas exceed the $95 \%$ confidence level.

blocking system almost 3 months before the event. For both sets of simulations the ensemble spread is relatively limited over eastern Europe while the areas of high uncertainty are mainly located over central Russia. Most members displaced the basic characteristics of the phase space and the velocity of the system shifting the center eastward and predicting a short-lived blocking pattern. Despite the fact of the long lead period, both January and April members provided similar confidence of the forecast reliability. Thus, almost all members initialized on April 2010 and having a 2-5 months lead time did not provide any further predictability improvement. Thus the predictability seems to be independent to the forecast horizon varying from seasonal to intraannual timescales.

The results of this study underline the main difficulties and limitations in the seasonal simulation of such high-impact weather event. Many studies confirm that the seasonal-scale predictability may be feasible but further work is required to properly assess these findings (Palmer and Anderson 1994; Hastenrath, 1995; Rowell, 1998; Lee et al., 2011). However, since the LAF method is operationally feasible, due to the fact that the LAF ensemble members can be produced during the normal operational cycle, it is of great importance to investigate furthermore the performance of such ensemble forecasting system. To this end, more high-impact weather events should be considered in order to evaluate the forecast skill and assess the effectiveness of the seasonal prediction.

Acknowledgements. The work described in this paper has been partially supported by the PreWEC project (MEXT-CT-2006-038331) 
funded by the European Union and the Greek General Secretariat for Research and Technology. The authors would like to thank the anonymous reviewers for their valuable comments and suggestions to improve the quality of the paper. The European Centre for Medium Range Weather Forecasts (ECMWF) and the National Oceanic and Atmospheric Administration (NOAA) are also acknowledged for the provision of the gridded analyses and the surface observational data.

Edited by: P. Nastos

Reviewed by: two anonymous referees

\section{References}

Barriopedro, D., Fischer, E. M., Luterbacher, J., Trigo, R. M., and García-Herrera, R.: The hot summer of 2010: redrawing the temperature record map of Europe, Science, 332, 6026, doi:10.1126/science.1201224, 2011.

Buizza, R.: Potential Forecast Skill of Ensemble Prediction and Spread and Skill Distributions of the ECMWF Ensemble Prediction System, Mon. Weather Rev., 125, 99-119, doi:10.1175/1520-0493(1997)125<0099:PFSOEP>2.0.CO;2, 1997.

Chowdary, J. S., Xie, S.-P., Lee, J.-Y., Kosaka, Y., and Wang, B.: Predictability of summer northwest Pacific climate in 11 coupled model hindcasts: Local and remote forcing, J. Geophys. Res., 115, D22121, doi:10.1029/2010JD014595, 2010.

Collins, W. D., Rasch, P. J., Eaton, B. E., Khattatov, B., Lamarque, J. F., and Zender, C. S.: Simulating aerosols using a chemical transport model with assimilation of satellite aerosol retrievals: Methodology for INDOEX, J. Geophys. Res., 106, 7313-7336, 2001

Collins, W. D., Rasch, P. J., Boville, B. A., Hack, J. J., McCaa, J. R., Williamson, D. L., Kiehl, J. T., Briegleb, B., Bitz, C., Lin, S. J., Zhang, M., and Dai, Y.: Description of the NCAR community atmosphere model (CAM 3.0), Tech. Rep. TN-464+STR NCAR, National Center for Atmospheric Research, Boulder, Colorado 80307-3000, 226, 2004.

Collins, W. D., Rasch, P. J., Boville, B. A., Hack, J. J., McCaa, J. R., Williamson, D. L., Briegleb, B. P., Bitz, C. M., Lin, S. J., and Zhang, M.: The formulation and atmospheric simulation of the Community Atmosphere Model: CAM3, J. Climate, 19, 21442161, 2006.

Dalcher, A., Kalnay, E., and Hoffman, R.: Medium-range lagged average forecasts, Mon. Weather Rev., 116, 402-416, 1988.

Dole, R. M. and Gordon, N. D.: Persistent anomalies of the extratropical Northern Hemisphere wintertime circulation: Geographical distribution and regional persistence characteristics, Mon. Weather Rev., 111, 1567-1586, doi:10.1175/15200493(1983)111<1567:PAOTEN>2.0.CO;2, 1983.

Dole, R., Hoerling, M., Perlwitz, J., Eischeid, J., Pegion, P., Zhang, T., Quan, X. W., Xu, T., and Murray, D.: Was there a basis for anticipating the 2010 Russian heat wave?, Geophys. Res. Lett., 38, L06702, doi:10.1029/2010GL046582, 2011.

Fiorino, M.: A multi-decadal daily sea surface temperature and sea ice concentration data set for the ERA-40 reanalysis, ERA-40 Project Report Series No. 12, 16, 2004.

Fischer, E. M., Seneviratne, S. I., Lüthi, D., and Schär, C.: Contribution of land-atmosphere coupling to recent Euro- pean summer heatwaves, Geophys. Res. Lett., 34, L06707, doi:10.1029/2006GL029068, 2007.

Ghelli, A., Garcia-Mendez, A., Prates, F., and Dahoui, M.: Extreme weather events in summer 2010: how did the ECMWF forecasting systems perform?, ECMWF Newsletter 125, 7, 2010.

Gneiting, T. and Raftery, A. E.: Weather forecasting with ensemble methods, Science, 310, 5746, doi:10.1126/science.1115255, 2005.

Hastenrath, S.: Recent advances in tropical climate prediction, J. Climate, 8, 1519-1532, 1995.

Hoffman, R. N. and Kalnay, E.: Lagged averaged forecasting, an alternative to Monte Carlo forecasting, Tellus A, 35, 100-118, 1983.

Hurrell, J., Meehl, G. A., Bader, D., Delworth, T. L., Kirtman, B., and Wielicki, B.: A unified modeling approach to climate system prediction, B. Am. Meteor. Soc., 90, 1819-1832, 2009.

Kalnay, E.: Atmospheric Modeling, Data Assimilation and Predictability, Cambridge University Press, 2003.

Kalnay, E., Kanamitsu, M., Kistler, R., Collins, W., Deaven, D., Gandin, L., Iredell, M., Saha, S., White, G., Woollen, J., Zhu, Y., Chelliah, M., Ebisuzaki, W., Higgins, W., Janowiak, J., Mo, K. C., Ropelewski, C., Wang, J., Leetmaa, A., Reynolds, R., Jenne, R., and Joseph, D.: The NMC/NCAR 40-Year Reanalysis Project, B. Am. Meteor. Soc., 77, 437-471, 1996.

Lau, K. M. and Kim, K. M.: The 2012 Russian heat wave/wildfires and Pakistan Flood: Teleconnection of Extremes, J. Hydrometeorol., 13, 392-403, doi:10.1175/JHM-D-11-016.1, 2012.

Lee, S. S., Lee, J. Y., Ha, K. J., Wang, B., and Schemm, J. K. E.: Deficiencies and possibilities for long-lead coupled climate prediction of the Western North Pacific-East Asian summer monsoon, Clim. Dynam., 36, 1173-1188, 2011.

Lupo, A. and Smith, P. J.: The interactions between a midlatitude blocking anticyclone and synoptic-scale cyclones that occurred during the summer season, Mon. Weather Rev., 126, 502-515, 1998.

Matsueda, M.: Predictability of Euro-Russian blocking in summer of 2010, Geophys. Res. Lett., 38, L06801, doi:10.1029/2010GL046557, 2011.

Oleson, K. W., Dai, Y., Bonan, G., Bosilovich, M., Dickinson, R., Dirmeyer, P., Hoffman, F., Houser, P., Levis, S., Niu, G.-Y., Thornton, P., Vertenstein, M., Yang, Z.-L., and Zeng, X.: Technical description of the Community Land Model (CLM). Technical Report NCAR/TN-461+STR, National Center for Atmospheric Research, Boulder, CO, 80307-3000, 174, 2004.

Palmer, T. N. and Anderson, D. L. T.: The prospects for seasonal forecasting-A review paper, Q. J. Roy. Meteor. Soc., 120, 755793, 1994.

Rasch, P. J. and Kristjánsson, J. E.: A comparison of the CCM3 model climate using diagnosed and predicted condensate parameterizations, J. Climate, 11, 1587-1614, 1998.

Rowell, D. P.: Assessing potential seasonal predictability with an ensemble of multidecadal GCM simulations, J. Climate, 11, 109_ 120, 1998.

Schär, C. and Jendritzky, G.: Climate change: Hot news from summer 2003, Nature, 432, 559-560, doi:10.1038/432559a, 2004.

Sedláček, J., Martius, O., and Knutti, R.: Influence of subtropical and polar sea-surface temperature anomalies on temperatures in Eurasia, Geophys. Res. Lett., 38, L12803, doi:10.1029/2011GL047764, 2011. 
Shapiro M. A., Shukla, J., Brunet, G., Nobre, C., Béland, M., Dole, R., Trenberth, K. E., Anthes, R., Asrar, G., Barrie, L., Bougeault, P., Brasseur, G., Burridge, D. M., Busalacchi, A., Caughey, J., Chen, D., Church, J., Enomoto, T., Hoskins, B. J., Hov, Ø., Laing, A., Le Treut, H., Marotzke, J., McBean, G., Meehl, G., Miller, M., Mills, B., Mitchell, J. M., Moncrieff, M., Nakazawa, T., Olafsson, H., Palmer, T. N., Parsons, D., Rogers, D., Simmons, A., Troccoli, A., Toth, Z., Uccellini, L., Velden, C., and Wallace, J. M.: An Earth-system prediction initiative for the twenty-first century, B. Am. Meteor. Soc., 91, 1377-1388, 2010.

Stott, P. A., Stone, D. A., and Allen, M. R.: Human contribution to the European heatwave of 2003, Nature, 432, 610-614, doi:10.1038/nature03089, 2004.

Uccellini, L. W., and Johnson, D. R.: The coupling of upper and lower tropospheric jet streaks and implications for the development of severe convective storms, Mon. Weather Rev., 107, 682703, 1979.
Webster, P. J., Toma, V. E., and Kim, H. M.: Were the 2010 Pakistan floods predictable?, Geophys. Res. Lett., 38, 40806, doi:10.1029/2010GL046346, 2011.

Weisheimer, A., Doblas-Reyes, F. J., Jung, T., and Palmer, T. N.: On the predictability of the extreme summer 2003 over Europe, Geophys. Res. Lett., 38, L05704, doi:10.1029/2010GL046455, 2011.

Williamson, D. L.: Time-split versus process split coupling of parameterizations and dynamical core, Mon. Weather Rev., 130, 2024-2041, 2002.

Zhang, M., Lin, W., Bretherton, C. B., Hack, J. J., and Rasch, P. $\mathrm{J}$.: A modified formulation of fractional stratiform condensation rate in the NCAR Community Atmosphere Model (CAM2), J. Geophys. Res., 108, 4035, doi:10.1029/2002JD002523, 2003. 